\title{
Theory of architectural morphogenesis (to the development of ideas of the phenomenological school)
}

\author{
Yuliya Yankovskaya ${ }^{1, *}$, Svetozar Zavarikhin ${ }^{1}$, Yuryi Kurbatov ${ }^{1}$, and Yuryi Pukharenko ${ }^{1}$ \\ ${ }^{1}$ Saint Petersburg State University of Architecture and Civil Engineering, 2nd Krasnoarmeyskaya \\ Street, 4, Saint Petersburg, 190005, Russia
}

\begin{abstract}
The paper is devoted to the historical and architectural aspect of the development of ideas about morphogenesis in architecture and built environment. The paper emphasizes the role and place of the phenomenological area of Russian architectural studies and its influence on the development of formative concepts. A certain innovation is the separation of two branches in the theory of morphogenesis: compositional and phenomenological. The phenomenological concept is considered in the development of ideas of A.G. Gabrichevsky.
\end{abstract}

\section{Introduction}

Traditionally, our Russian architectural and theoretical thought is associated with the development of compositional ideas about morphogenesis in architecture. Over a long period of time, the theory of composition was a discipline of a recommendatory nature, aimed at the needs of architectural design. For almost half a century it held the position of one of the main, permanent and obligatory subjects of study in architectural science. How legitimate is the selection of an alternative phenomenological school in Russian theory against this background? Why is it necessary to single out the phenomenological school of morphogenesis, which clearly did not have such a huge number of followers in Russian theory as "compositional" one? This question is debatable.

\subsection{Background and scientific context}

Nowadays, phenomenological traditions in architectural theory are mainly associated with the names of Western scientists, and this is not entirely legitimate. Already in the 1920s, the fundamental phenomenological theoretical concept of A.G. Gabrichevsky was formed in Russia [1] (Fig. 1. a), which in many respects anticipated the later Western and contemporary philosophical and theoretical interpretations of architectural morphogenesis. Unfortunately, a comprehensive acquaintance with the Gabrichevsky's works on the morphology of art was not possible until recently, the phenomenological analysis of the architecture of the 1920s was forgotten, and later works of foreign authors (M. Merlo-Ponty

\footnotetext{
*Corresponding author: jul3203226@gmail.com
} 
[2], Cr. Norberg- Schulz [3-5] (Fig. 1, 2), etc.) replaced it. On the other hand, the disclosure of morphogenesis through the concept of the physical experience of space, barriers and boundaries, the relations of the "core and shell", "gesture and trace" are more consistent with the latest non-linear, mirror-like and dissolving in the environment, ghostly transparent architecture.
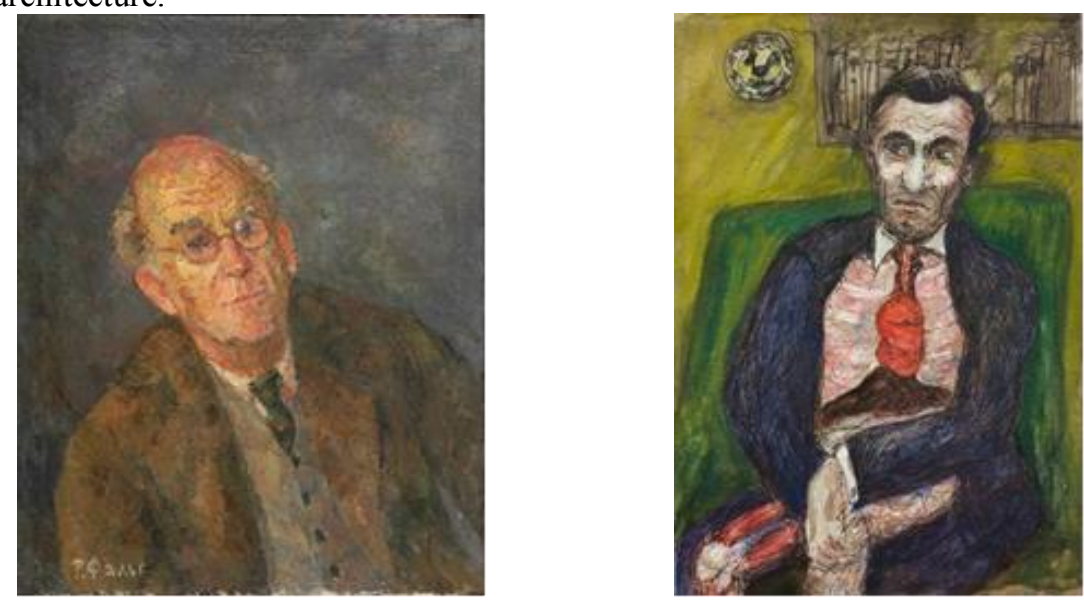

a) b)

Fig. 1. a) Portrait of A.G. Gabrichevsky (by R. Falk), b) Portrait of M. Merlo-Ponty (by M. Heiter).

Let's refer to history and try to understand whether it is possible to distinguish a phenomenological school in Russian architectural studies. Art studies in Russia began to form quite late. Until the 1910s, it was an auxiliary discipline in classical philology and archeology. Only in 1907, a branch of the theory and history of art appeared at Moscow University. The study of the formal method by Russian scientists took place through internships in Germany by A. Gabrichevsky, V. Favorsky, who translated "The problem of form in the fine art of Hildebrand" [6, 7] and others. The study of the formal method and its critical analysis lasted in Russia until the end of 1920s [8]. The advantages and disadvantages of the formal method in its western interpretation formed the basis of various areas in creating an independent domestic art science, which became the main task of the State Academy of Arts. First, there was created Physico-psychological department (1921, chairman - V. Kandinsky), and then - Philosophical department (1922, chairman - G. Shpet). The department included such figures as N. Uspensky, I. Zholtovsky, A. Gabrichesky, R. Falk, G. Shpet, B. Vipper, V. Kandinsky, P. Florensky. M. Kogan, A. Losev and etc. also participated in the work. In 1929, the State Academy of Arts was closed. A variety of concepts and areas that did not comply with Marxism was rejected by the Soviet state [8]. 
Fig. 2. Cr. Norberg-Schulz.

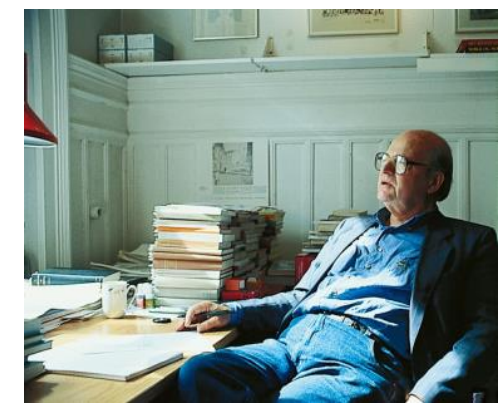

In the period under consideration, there were a number of areas in Russia that interpreted the ideas of the formal school in different ways, connecting them with the tradition of psychoanalysis, with phenomenological influences, etc. The following concepts are represented as basic ones: A. Gabrichevsky (one of the founders of Russian architectural studies, who drew the line with the Hildebrand school) connected volume / mass and space into an inseparable pair, which is the basis of morphogenesis, the embodiment of static and dynamic principles. Architect N. Ladovsky and his school (V. Krinsky, I. Lamtsov, M. Turkus) considered spatial relations to be the basis of morphogenesis. In their opinion, everything else depended on the solution of the problems of space. The methods of architectural composition served to identify the geometric and other characteristics of the internal and external architectural space. I. Golosov put the architectural mass (large volumetric form) in the first place and preferred volumetric elements in matters of morphogenesis. K. Melnikov put such concepts as internal tension and external looseness of the architectural form at the forefront. I. Leonidov considered the interaction of simple geometric shapes. A. Vesnin emphasized the aesthetic possibilities of materials and structures. Ya. Chernikhov conducted his searches in the field of graphic combinatorics of the correct geometric shapes and lines, having a great influence on the development of compositional propaedeutic courses of many modern architectural schools. So why is the question of singling out a phenomenological school, or rather the separation of compositional and phenomenological schools, being raised against this background? One source, interdependence and mutual influences - all this is undeniable, but let's carefully analyze the phenomenological concept of Gabrichevsky in order to reveal the difference in methodological approaches and worldviews, which gives reason to distinguish the phenomenological school as an independent one $[8,11]$.

\subsection{Philosophical context}

The phenomenological approach, along with behaviorism, are the leading philosophical and psychological trends today. The emergence of this trend in the philosophy of culture at the turn of the 19-20 centuries traditionally associated with the name of E. Husserl. Although today there are concepts that reveal phenomenological traditions dating back to Plato's doctrine of eidos, Aristotle's doctrine of entelechy, doctrine of antient stoics about the fire logos, Neoplatonists - about existing, striving for good, Goethe's "praphenomenon" theory, which proved that all phenomena and creatures have their ideal type, prototype, which morphologically correspond to at all phases of their evolution. The main thing in which all thinkers who continue and develop phenomenological traditions in the 20th and 21st centuries converge is a general cultural orientation in different areas and forms of human consciousness and the disclosure of axiological world of man $[8,11]$. 


\section{Materials and methods}

The study is in line with the historical and theoretical field of architecture, which explains the specifics of the choice of approaches and working methods.

The phenomenological approach determined the initial worldview of the authors. It is supplemented by the choice of structures as an analytical tool for constructing theoretical models.

Also, traditional methods are used in the work: the method of analysis of literary sources, the comparative method and the method of historical and genetic analysis, which are used when considering the evolution of non-stylistic ideas about morphogenesis in architecture and their philosophical and psychological conditioning, the modeling method in building conceptual research models.

\section{Results and discussion}

\subsection{Phenomenological concepts of A.G. Gabrichevsky}

It is possible to attribute A.G. Gabrichevsky to phenomenologists, first of all, on the basis of the specificity and continuity of his philosophical views formed under the influence of his home-based teacher of logic - G.G. Shpet, who attended the lectures of E. Husserl in Göttingen in 1910-1913 and was not only a listener, but also his student and friend. It is believed that Shpet was the leading representative of phenomenology in Russia. In the student days (in 1910s), A.G. Gabrichevsky became close to the Russian existentialist N. Berdyaev. In the 1920s, Andrei Bely fell into his circle of contacts, who in his literary works embodies a concept close to a phenomenological one - a physical-experiencing and creating-transforming environment, connecting together the conscious and pre-conscious layers of the individual self (see, for example, the works of the 1910-1920s: "Petersburg", "Kotik Letaev" [9]), which in turn had a powerful influence on the philosophy of culture of Bakhtin, Losev, on the late phenomenological hermeneutics of Shpet. Secondly, Gabricevsky himself practices "phenomenological analysis", and the circle of his philosophical substantiations of the morphology of art is phenomenological.

The basic one for Gabrichevsky [1] is the question of the primary elements of the "artistic-plastic experience": space and mass, categories of thing and life, cores and shells. We will try to uncover the provisions that are most significant for the emergence of the Russian phenomenological school of architectural studies in the 1920s and 1930s, the development of which was forcibly interrupted in the future. We will not dwell on the "space-mass" pair, which has always been given great attention in Russian architectural theory.

The first position is the physicality of spatial experience. The body "is the highest and last criterion of all spatial relations and the whole system of values, which are located in concentric circles around an ideal organic unit" [1, p. 404]. It carries primary contents:

- the body is the supreme value, the supreme criterion of the system of values according to which things are arranged depending on proximity to a person;

- the body is the beginning of constancy - the opposite of unconscious processuality, a symbol of the implementation of three basic vital instincts (self-preservation, assimilation, reproduction);

- the stability of the body is the experience of the essential as opposed to random.

The second position is a thing as fixing a useful gesture of a person. A thing expresses its purpose in form, form fixes and perpetuates a person's gesture and makes it a sign of artistic content, transfers it into the sphere of pure expressiveness. Matter acquires the 
character of a gesture as a result of resistance to a space bursting into a shell. Two types of gesture should be distinguished: plastic - a gesture that creates plastic value, dynamic - a gesture that encircles the core (the core serves as a potential field of action for the movements of a human individual or collective).

The third position is the form as a trace of "living on the dead"; the trace left behind by the living gesture of a moving organism is fixed by the construction of a material shell delimiting the amount of space necessary for this movement, which must be preserved, ensuring repetition and separation from the self-destructing time stream. The history of architectural forms is the history of human identity and well-being. The form is:

- the constant border between the Self and the non-Self, self-affirmation of the creator, the creation of the world in the image and likeness;

- the fence separating and protecting the individual as the supreme value from the variability of the unconquered elements;

- an ideal shell created by an ideal, substantial core.

The fourth position is the shell-border. A cultured person is surrounded by a system of expressive shells, concentrically located around his body as the supreme value (from clothing to the building, the city ... to the idea of the universe). These circles are stages on the path of constantly expanding field of activity of the individual on the path of gradually subordinating to him the surrounding non-Self. The typicality of the shell perceived from the inside is associated with adaptation to an extra-individual gesture and the stability of the space allotted to it. Types of shells can be distinguished depending on:

- the scope and nature of the activity fixed by the shell, the mobility of the shell and on the number of human units, which determines the spatial volume;

- the degree of its impermeability and can be seen either from the tactile and visual properties of its surface, since they reveal its internal structure, or by detecting this structure in cross sections ("door and window as certain spatial and motion forms of fixation of motion complexes that connect the spatial core to the dynamics of the outside world).

The fifth position is an image-character. Artistic image (Gestalt) - the creative core of the product, directly given in the form of an object. "The form itself is an act, it is immanent to the process, secondary, volatile, fugitive, no more than a gesture of an internal dynamic core" [1, P. 156].

A work of art as an identity of sign and signified is an image. A work of art is a product; it genetically and empirically involves overcoming the dualism of the Self and the non-Self, creator and creature, design and material, where both of its components form an indissoluble unity.

The concept of "artistic image", analyzed by A.G. Gabrichevsky, turned to the creator and implies the presence of an "ideal creative subject" as a formative spatial core that isolates a valuable part of space. "The creative subject leaves his trace on the dead non-Self, imprinting his living image on it" [1, P. 155]. This subject is: a deity in religious art, an individual or a family - in a private building, a collective or state - in a public building. In the hierarchy of subjects and objects of creativity from the side of their existential connection, a certain higher synthetic type is essentially postulated: this subject is a genius, an object is a work of art.

The sixth position is the ambiguity of the structure of an image in architecture. This ambiguity is related to:

- the synthetic reality of the artistic image (Gestalt), which is made up of the relations of the assimilated component (Inhalt - the canon, ready-made forms and materialized elements) and the assimilative component (Gehalt - the creative beginning); where the artistic image - is the interpenetration of the element of formation and the element of becoming. "The relationship between Inhalt and Gehalt is one of the most important criteria 
for the analysis of formal content for building a specific morphology of a product" [1, P. 134];

- two types of artistic and expressive design of a thing: plastic, where a thing is a sign of self-valuable closed being and tectonic, where a thing is a sign of itself as matter, as a means of some value content that lies beyond it (a carrier of value motion contents that are imprinted on this thing);

- morphology, and at the same time it becomes two-stage: the core and the shell, the core-shell and the environment (the force field of the building is its projection into space);

- allegorical and typical nature of architectural form: allegorical nature is revealed through the architectural form as an image of the dialogue of a typical generic act of a person as an individual and matter itself.

In later works A.G. Gabrichevsky of 1940-1950-ies, architectural imagery is associated with the consideration of architecture as a language, which was developed by V. Marcuson. Here we can highlight the following points:

- connection of material culture with the field of language;

- connection "form-word-form" created by man is at the same time the word as a means of expression of thought;

- consideration of the history of architecture as a series of expressive systems - by analogy with a language that has a logical structure (for example, consideration of the syntax of ancient architecture as a frame, beam, support system).

It should be emphasized that, unfortunately, the complex philosophical and art criticism system of Gabrichevsky, which, in essence, is an alternative to the compositional concept, which received the greatest influence in Russian architectural theory, did not receive full development, although it had like-minded people, such as V. Kandinsky, P. Florensky, V Favorsky and others, and the followers, such as D. Arkin, V. Markuson and others. This can be explained, on the one hand, by the prevailing political and ideological situation in the country in those years, and on the other, by the orientation of Gabrichevsky on the history of architecture and the order neoclassicist contemporary architecture in the absence of interest in the latest forms of that time [8]. In the 1920s and 1930s, this concept was organically woven into the ideological field of ideas of the Russian phenomenological (G. Shpet, M. Mamardashvili), existential (N. Berdyaev, L. Shestov), religious and philosophical (P. Florensky, V. Soloviev, A. Losev, I. Ilyin), physical and Dionysian (V. Rozanov - an apologist for Russian physicality) thoughts. The Russian phenomenological school anticipated and revealed a number of trends that appeared much later in the works of western architectural theorists, such as Cr. Norberg-Schulz, Cr. Dey, H. MutanyolThornberg (developing the concept of the "trace"), and who came to Russia through the interpretations of foreign authors and are associated with the names of M. Heidegger, M. Merlo-Ponty, P. Ricoeur, and, in addition, with later concepts, developing ideas and traditions of Husserl in modern postmodernism, Gadamer, Foucault, Derrida, J.-F. Lyotard, J. Lacan, Ricoeur, J. Deleuze and others.

Let us return to the question: what defines a "school"? The presence of recognized sources, areas of established ideas and concepts that ensure reproducibility and continuity of traditions of principles and methods. The distinguished phenomenological school has all this - there are sources, there is an established philosophical foundation, there is a comprehensive art criticism concept that is reproducible both in works of a philosophical and art criticism character (for example, the work of G.N. Lola, who considers design as an experience of metaphysical transcription, an ontological concept of a thing and a subjectspatial environment by T. Yu. Bystrova, the concept of transiency and marginality of modern morphogenesis by N.N. Mosorova, metaphorical formation by G.V. Zherdev) and in purely architectural research: in the analysis of architectural images of D. Arkin; in "barrier theories" by I.G. Lezhava, A.V. Bokov; in the analysis of the "boundaries and 
boundedness of architecture" by O. Yavein, in theories that reveal the connection of the architectural form as a gesture-sign with the chthonic elements - V. Markuson and A. Rappoport et al. [8]. And most importantly, there is a demand and methodological productivity in relation to the latest architectural morphogenesis. In the newest mirror-like, ghostly transparent, nonlinear contemporary architectural morphogenesis, formative concepts are seen as more productive: core-shells, shell-borders, spatial volumes, gesture and trace, more relevant to both material and philosophical conditioning of modern architecture [8, 10, 11, 12-14].

\subsection{Two schools of architectural morphogenesis}

Why should domestic concepts of out-of-style morphogenesis be divided into at least two alternative schools, the traditional one, implanted in the educational process "compositional" and "phenomenological"?

These schools had a common root - the formal method, their development, and was characterized by mutual influences, especially at the initial stages, but fundamentally these two schools are distinguished by the difference in philosophical positions [8, 11]:

- position in a compositional school: a person - opposing an architectural object; the specificity of perception (mainly visual) determines the approaches and forms techniques and rules for creating new objects;

- position in the phenomenological school: a person - experiencing his physical presence in the world of things, where the vitality of his gesture, leaving a trace on dead matter, gives rise to an object (or system of objects) as a shell-border between the Self and the nonSelf.

In addition, the possibility of being identified as an independent area is determined by the distinctive features of the phenomenological school, which are fixed by the above provisions, such as: physicality of spatial experience, the world of things as a fixation of a useful gesture of a person, form as a trace, shell as a border, ambiguity of the image structure in architecture. Based on the basic principles of the phenomenological and compositional schools, the phenomenological school is conceptually initial, because it is possible to deduce all the provisions of the compositional school from its provisions, but not vice versa. The phenomenological school, in contrast to the compositional one, proceeding from its philosophical conditionality, was oriented toward revealing the value and semantic world of a person in a vital morphogenesis gesture and fixing it as a "trace" embodied in material form.

The phenomenological tradition initially turned to the sources - the physicality of spatial experience and, accordingly, the "barrier" ability of morphogenesis; compositional school refers to the regulation of formative creative activity. The priority of the development of the national compositional school was associated, on the one hand, with the support of its ideas by representatives of the Russian architectural avant-garde in the 1920s, and on the other, with the official support of the Soviet state in the 1940s. The phenomenological school was not accepted and appreciated due to both being ahead of the theory of the existing material means of architecture, when there were no modern shell-forms, "non-linear" forms embodiments of a gesture, transparent multilayer barriers, etc., and the obvious ideological discrepancies.

\section{Conclusion}

The assertion about the existence of a domestic phenomenological school that has outstripped and anticipated modern studies and concepts of morphogenesis in modern architecture can be considered as a hypothesis, which is confirmed in a textual analysis of 
A.G. Gabrichevsky and modern works on morphogenesis, and as the basis for further theoretical development of domestic traditions that do not lose their relevance. Of course, speaking of the possible modern development of the phenomenological area in the domestic theory of architecture, one should take into account all the best that has been accumulated by the compositional school.

\section{References}

1. A.G. Gabrichevsky, Morphology of art (AGRAF, Moscow, 2002)

2. M. Merlo-Ponty, Phenomenology of perception (Routledge \& Kegan Paul, Paris, 1962)

3. C. Norberg-Schulz, Existence, Space and Architecture (Praeger, New York, 1971)

4. Y. Yankovskaya, A. Merenkov, IOP Conference Series: Materials Science and Engineering, 262, 012134 (2017)

5. Y. Yankovskaya, Proceedings of the Latvia University of Agriculture Landscape Architecture and Art, A. Ziemelniece (ed.), 2, 50-59, Latvia University of Agriculture, Jelgava (2013)

6. H. Wölfflin, Interpretation of art (Dolphin, Moscow, 1922)

7. A. Hildebrand, The problem of form in the visual arts and collection of articles (Musaget, Moscow, 1914)

8. Yu.S. Yankovskaya, Architectural object: image and morphology (MArchI, Moscow, 2006)

9. A. Bely, Symbolism as a world understanding (Republic, Moscow, 1994)

10. Grammaire de la Architecture (Dessan et Tolra, Paris, 2002)

11. Y. Yankovskaya, A. Merenkov, Proceedings of the Latvia University of Agriculture Landscape Architecture and Art, A. Ziemelniece (ed.), 2, 77-84, Latvia University of Agriculture, Jelgava (2013)

12. Yu.I. Kurbatov, Bulletin of civil engineers, 4 (63), 23-26 (2017)

13. S. Zavarichin, V. Lisovskij, World Applied Sciences Journal, 23, 149-152 (2013)

14. S. Zavarikhin, N.G. Tran, Architecture and Engineering, 1, 33-40 (2016) 